\title{
RESISTÊNCIA DE GENÓTIPOS DE BATATA-DOCE AO MAL-DO-PÉ
}

\author{
Kleycianne Ribeiro Marques ${ }^{1}$, Aline Torquato Tavares ${ }^{2 *}$, Danilo Alves Porto da Silva \\ Lopes $^{3}$, Gil Rodrigues dos Santos ${ }^{4}$, Valeria Gomes Momenté ${ }^{5}$, Ildon Rodrigues do \\ Nascimento $^{4}$
}

\footnotetext{
${ }^{1}$ Doutora em Produção Vegetal - Departamento de Agronomia, Universidade Federal do Tocantins, Campus de Gurupi - TO.

2 Pesquisadora Pnpd do Programa de Pós-Graduação em Produção Vegetal - Melhoramento de Plantas, Departamento de Agronomia, Universidade Federal do Tocantins, Campus de Gurupi - TO. *E-mail do autor correspondente: alinet4t@yahoo.com.br

${ }^{3}$ Mestrando em Produção Vegetal - Departamento de Agronomia, Universidade Federal do Tocantins, Campus de Gurupi - TO.

${ }^{4}$ Professor da área de Fitossanidade e Melhoramento de Plantas - Departamento de Agronomia, Universidade Federal do Tocantins, Campus de Gurupi - TO.

${ }^{5}$ Professora da área de Fitotecnia - Departamento de Agronomia, Universidade Federal do Tocantins, Campus de Gurupi - TO.
}

RESUMO: O mal-do-pé é uma das doenças mais agressivas na cultura da batata-doce, acarretando perdas significativas. $\mathrm{O}$ trabalho objetivou avaliar a resistência de genótipos de batata-doce ao mal-do-pé, causado por Plenodomus destruens Harter em condições de laboratório, casa de vegetação e campo experimental. Em laboratório, foi avaliada a agressividade de 24 isolados locais de $P$. destruens, em delineamento inteiramente casualizados. Os isolados foram inoculados em dois genótipos de batata-doce. Em casa de vegetação foi avaliada a resistência de 36 genótipos de batata-doce à doença. $\mathrm{O}$ delineamento experimental utilizado foi inteiramente casualizado, em esquema fatorial $36 \times 2$, sendo 36 genótipos de batata-doce e 2 isolados de mal-do-pé. No campo experimental foi avaliada a resistência de 20 genótipos de batata-doce ao mal-do-pé. O ensaio foi instalado em delineamento do tipo blocos casualizados com três repetições. Os isolados de P. destruens: IMPG\#10, IMPG\#11 e IMPG2 foram os mais agressivos aos caules inoculados em testes de laboratório. Os genótipos de batata doce BDFMI\#10, BDFMI\#14, BDFMI\#58, BDFMI\#106，2007HSF0128，2007HSF0613，2007HSF0906， BDFMI\#28, BDFMI\#88, BDFMI\#57, BDFMI\#31, BDFMI\#36, BDFMI\#78, Itajuba, BDFMI\#59 e BDFMI\#89 foram considerados tolerantes ao mal-do-pé em casa de vegetação. Em campo, os genótipos mais produtivos foram BDFMI\#16, Duda, BDFMI\#04, BDFMI\#93 e 2007HSF0128. Todos os genótipos testados foram infectados pelo patógeno e aqueles com maiores níveis de tolerância à doença foram BDFMI\#57 e BDFMI\#40.

Palavras-chave: Ipomoea batatas. Plenodomus destruens. Reação. 


\title{
RESISTANCE OF SWEET POTATO GENOTYPES TO FOOT-ROT
}

\begin{abstract}
The crown sheath rot one of the most aggressive diseases in the sweet potato crop, causing significant losses. The work aimed to evaluate the resistance of sweet potato genotypes to foot malaria caused by Plenodomus destruens Harter in laboratory conditions, greenhouse and experimental field. In the laboratory, the aggressiveness of 24 local isolates of $P$. destruens was evaluated in a completely randomized design. The isolates were inoculated in two sweet potato. In greenhouse the resistance of 36 sweet potato genotypes to the disease was evaluated. The experimental design was completely randomized in the $36 \times 2$ factorial scheme, 36 sweet potato genotypes and 2 foot-rot isolates. In the experimental field, the resistance of 20 sweet potato genotypes to foot-rot was evaluated. The experiment was installed in a randomized complete block design with three replicates. Isolates of $P$. destruens IMPG\#10, IMPG\#11 and IMPG\#2 were the most aggressive to the stems inoculated in laboratory tests. The sweet potato genotypes BDFMI\#10, BDFMI\#14, BDFMI\#58, BDFMI\#106, 2007HSF0128, 2007HSF0613, 2007HSF0906, BDFMI\#28, BDFMI\#88, BDFMI\#57, BDFMI\#31, BDFMI\#36, BDFMI\#78, Itajuba, BDFMI\#59 and BDFMI\#89 were considered to be tolerant to foot-rot, in greenhouse. In the field, the most productive genotypes were BDFMI\#16, Duda, BDFMI\#04, BDFMI\#93 and 2007HSF0128. All genotypes tested were infected by the pathogen and those with the highest levels of tolerance to the disease were BDFMI\#57 and BDFMI\#40.
\end{abstract}

Key words: Ipomoea batatas. Plenodomus destruens. Reaction.

\section{INTRODUÇÃO}

A batata-doce (Ipomoea batatas (L). Lam.), é uma espécie dicotiledônea pertencente à família Convolvulaceae, considerada uma cultura rústica, de ampla adaptação, com ampla diversidade fenotípica e genotípica (ANDRADE JÚNIOR et al., 2012). É uma espécie cultivada em todas as regiões do Brasil, e principalmente, como cultura de segurança alimentar em pequenas propriedades rurais.

Apesar do elevado potencial produtivo, demonstrado por produtividades experimentais relatadas até $98 \mathrm{Mg} \mathrm{ha}^{-1}$ por Gonçalves Neto (2011), a cultura da batata-doce ainda se caracteriza pela baixa produtividade devido ao baixo nível tecnológico empregado, evidenciado pelo uso limitado de irrigação, fertilizantes e defensivos agrícolas e a escassez de variedades com maior capacidade produtiva e adaptadas às diversas regiões (CAVALCANTE et al., 2009).

Outro fator que tem contribuído para a baixa produtividade da cultura são as doenças. Dentre estas, a mais importante tem sido "o mal-do-pé", que tem como agente causal o fungo Plenodomus destruens Harter, um patógeno de solo específico da batata-doce, capaz de reduzir em até $80 \%$ a produtividade da cultura, principalmente em áreas onde o cultivo é intenso e sucessivo (CLARK et al., 2009).

Cultura Agronômica, Ilha Solteira, v.27, n.2, p.287-301, 2018 
Este patógeno pode infectar as plantas durante todo o ciclo de cultivo e as raízes durante o armazenamento. Os sintomas da doença são observados em reboleiras no campo através da presença de lesões escuras na base das hastes que provocam murchas, amarelecimento das folhas e morte da planta. Nas raízes, provoca podridão seca e escura, que continua a progredir lentamente durante o armazenamento, tornando-as inúteis ao consumo (NEVES et al., 2010).

O início da doença na lavoura se dá pelo uso de ramas sementes contaminadas oriundas de lavouras doentes ou ainda obtidas em viveiros contaminados. A partir das ramas doentes desenvolvem-se as estruturas do fungo na base da planta, onde se produz grande quantidade de esporos que são disseminados principalmente por respingos, contaminando outras partes da planta, porém não desenvolvendo aí as manchas. Portanto, a ramas podem permanecer aparentemente sadias, se tornando fonte de inóculo para novos plantios. $\mathrm{O}$ fungo é também disseminado pela incorporação dos restos da cultura, permanecendo no solo por vários anos (PEREIRA et al., 2011).

As medidas de controle do mal-do-pé consistem na rotação de culturas por pelo menos dois anos para reduzir a população do patógeno em áreas infestadas (LOPES e SILVA, 1993), e principalmente no uso de materiais propagativos sadios. Contudo, o uso de cultivares resistentes ou tolerantes consiste na melhor forma de controle e/ou manejo da doença (CAVALCANTI et al., 2002; PEREIRA et al., 2011).

Dada a importância do mal-do-pé em condições tropicais de cultivo, o presente trabalho objetivou avaliar a reação de genótipos de batata-doce ao mal-do-pé em laboratório, casa de vegetação e condição de campo.

\section{MATERIAL E MÉTODOS}

Ensaios foram conduzidos no Munícipio de Gurupi, Tocantins (11 ${ }^{\circ} 43^{\prime} 45^{\prime}$ 'S e 49 $04^{\prime} 07^{\prime}$ 'O, altitude 280 m, região sul do Estado), durante os meses de janeiro a agosto de 2015.

\section{Seleção de isolados de Plenodomus destruens quanto à agressividade em genótipos de batata-doce}

Foi avaliada a agressividade de 24 isolados locais de mal-do-pé coletados nas cidades de Palmas (região Central) e Gurupi (região Sul) no Estado do Tocantins em delineamento inteiramente casualizados com dois genótipos experimentais de batata-doce (BDFMI\#40 e 2007HSF1405). Os isolados foram coletados em plantas doentes procedentes de lavoura comercial. Após isolamentos em meio BDA e obtenção de cultura pura, de acordo com metodologia proposta por Dhingra e Sinclair (1995), os isolados foram identificados sob lupa e microscópio ótico com o apoio da literatura específica (BARNETT e HUNTER, 1998; SUTTON, 1980).

Cultura Agronômica, Ilha Solteira, v.27, n.2, p.287-301, 2018 
A inoculação do patógeno foi feita com discos contendo micélios e conídios que foram fixados com alfinetes estéreis em ramas coletadas de plantas sadias dos genótipos BDFMI\#40 e 2007HSF1405. Como testemunhas foram consideradas ramas sadias sem inoculação do disco micelial e rama sadia com a inoculação apenas do alfinete estéril. Após a inoculação, as ramas foram colocadas em gerbox contendo duas camadas de papel filtro umedecido com água estéril e mantidas por 48 horas em câmara úmida no escuro, com temperatura variando de 28 a $33^{\circ} \mathrm{C}$.

Decorridos quatro dias da inoculação, a agressividade foi avaliada através da medida do comprimento da lesão formada no caule por meio de uma régua.

\section{Resistência de genótipos de batata-doce ao mal-do-pé em casa de vegetação}

Foram avaliados 36 genótipos de batata-doce cultivados em tubetes de polipropileno de $55 \mathrm{~cm}^{3}$, contendo uma mistura de esterco, solo, areia e substrato comercial Bioflora ${ }^{\circledR}$ esterilizado, na proporção de 1:2:1:1, respectivamente.

O delineamento experimental utilizado foi inteiramente casualizado com 5 repetições, no esquema fatorial 36x2, sendo o primeiro fator constituído por 36 genótipos de batatadoce e o segundo fator constituído por dois isolados de $P$. destruens previamente selecionados no ensaio anterior, identificados como IMPG\#010 e IMPG\#11. Cada parcela consistiu de cinco plantas. Como testemunha foi utilizada uma parcela de cada genótipo que não recebeu inoculação.

Os 36 genótipos de batata-doce avaliados foram: seis cultivares (Princesa, Itajuba, Amanda, Duda, Júlia e Marcela) e 26 genótipos experimentais selecionados com base na produtividade e teor de amido (BDFMI\#04, BDFMI\#10, BDFMI\#11, BDFMI\#14, BDFMI\#16, BDFMI\#28, BDFMI\#31, BDFMI\#36, BDFMI\#38, BDFMI \#40, BDFMI\#42, BDFMI\#51, BDFMI\#57, BDFMI\#58, BDFMI\#59, BDFMI\#70, BDFMI\#78, BDFMI\#88, BDFMI\#89, BDFMI\#93, BDFMI\#94, BDFMI\#106, 2007HSF0128, 2007HSF0613, 2007HSF0906, 2007HSF1031, 2007HSF1035, 2007HSF1105, 2007HSF1405 e 2007HSF2210).

De cada genótipo foram obtidos mudas de mini-estacas (dois nós) que foram inoculadas aos 20 dias após plantio (DAP) utilizando suspensão de 1,6x10 conídios $\mathrm{mL}^{-1}$, ajustada com auxilio de uma Câmara de Neubauer.

Após a inoculação as plantas foram mantidas por 24 horas em câmara úmida no escuro, com temperatura variando de 28 a $35^{\circ} \mathrm{C}$. Após esse período as plantas foram levadas para casa de vegetação, onde permaneceram até o final das avaliações.

As avaliações da resistência foram iniciadas quatro dias a inoculação, medindo-se o comprimento da lesão formado na rama, com uma régua graduada.

Cultura Agronômica, Ilha Solteira, v.27, n.2, p.287-301, 2018 


\section{Produtividade, teor de matéria seca e reação ao mal-do-pé em genótipos de batata- doce}

Foram avaliadas em condições de campo um total de 20 genótipos de batata-doce, sendo 15 genótipos experimentais, pertencentes ao Programa de Melhoramento Genético da Universidade Federal do Tocantins (BDFMI\#04, BDFMI\#10, BDFMI\#16, BDFMI\#31, BDFMI\#38, BDFMI\#40, BDFMI\#51, BDFMI\#57, BDFMI\#70, BDFMI\#89, BDFMI\#93, BDFMI\#94, BDFI\#106, 2007HSF0128 e 2007HSF1405) e 5 cultivares testemunhas (Amanda, Duda, Itajuba, Marcela e Princesa).

O solo escolhido para a condução do experimento foi classificado como um Latossolo Vermelho Amarelo (EMBRAPA, 2013), onde foi cultivada batata-doce e caracterizado por possuir fonte natural de inóculo.

O ensaio foi instalado em delineamento do tipo blocos casualizados com três repetições. Cada parcela foi formada por seis plantas, sendo considerada como parcela útil as quatro plantas centrais. $\mathrm{O}$ plantio foi feito com mudas sadias produzidas em tubetes e transplantado para canteiros de $0,70 \mathrm{~m}$ de largura com espaçamento entre eles de $1,0 \mathrm{~m}$. O espaçamento entre plantas em cada canteiro foi de $0,50 \mathrm{~m}$ e entre as linhas foi de $1,7 \mathrm{~m}$.

A adubação de plantio foi feito segundo recomendação da cultura (FILGUEIRA, 2008) e resultado da análise de solo, conforme (Tabela 1). No plantio, incorporado ao canteiro, foi aplicado $20 \mathrm{~kg} \mathrm{ha}^{-1}$ de nitrogênio, $40 \mathrm{~kg} \mathrm{ha}^{-1}$ de potássio e $120 \mathrm{~kg} \mathrm{ha}^{-1} \mathrm{de}$ fósforo, usando como fontes ureia, cloreto de potássio e superfosfato simples, respectivamente. A adubação de cobertura ocorreu aos 20 e 40 DAP com $20 \mathrm{~kg} \mathrm{ha}^{-1}$ de N e $40 \mathrm{Kg} \mathrm{ha}^{-1}$ de potássio, usando uréia e cloreto de potássio como fontes, respectivamente.

Tabela 1. Características químicas do solo na profundidade de $0-20 \mathrm{~cm}$ do local onde foi conduzido o ensaio de avaliação dos genótipos de batata-doce ao mal do pé em Gurupi, região sul do estado do Tocantins. UFT, Gurupi-TO, 2014.

\begin{tabular}{|c|c|c|c|c|c|c|c|c|}
\hline $\left.\mathrm{pH}_{(} \mathrm{H}_{2} \mathrm{O}\right)$ & $\mathrm{P}$ & $\mathrm{K}$ & $\mathrm{Ca}^{2+}$ & $\mathrm{Mg}^{2+}$ & $\mathrm{Al}^{3+}$ & $\mathrm{H}+\mathrm{Al}$ & $\mathrm{V}$ & M.O. \\
\hline \multirow{2}{*}{6,2} & $\mathrm{Mg} \mathrm{dm}^{-3}$ & \multicolumn{4}{|c|}{-------------cmoc $\mathrm{dm}^{-3}$-------------- } & & $\%$ & dag $\mathrm{kg}^{-1}$ \\
\hline & 26,1 & 107 & 2,5 & 1,4 & 0,0 & 1,5 & 74 & 1,8 \\
\hline
\end{tabular}

O ensaio foi conduzido sob condições de irrigação suplementar por aspersão, nos meses com ausência de chuvas, foi realizada uma vez ao dia, de acordo com a demanda da cultura, foram realizadas capinas manuais aos 20,40 e 60 dias após transplantio, não houve incidência significativa de pragas e a colheita foi realizada 180 DAP e as características avaliadas foram:

- Produtividade de raízes $\left(\mathrm{Mg} \mathrm{ha}^{-1}\right)$ : obtida pela pesagem das raízes das plantas da parcela útil e o resultado foi convertido para $\mathrm{Mg} \mathrm{ha}^{-1}$.

- Severidade do mal-do-pé: medida do comprimento das lesões com régua graduada em centímetros em plantas da parcela útil com ocorrência natural do mal-do-pé.

Cultura Agronômica, Ilha Solteira, v.27, n.2, p.287-301, 2018 
- Área Abaixo da Curva de Progresso do Mal-do-pé (AACPM): com os dados de severidade de cada avaliação foi calculado, para cada genótipo, os valores da Área Abaixo da Curva de Progresso da Doença, conforme Shaner e Finney (1977), pela fórmula:

$$
A A C P D=\sum_{i=1}^{n}\left[\frac{Y_{i+1}+Y_{i}}{2}\right] *\left[\left(T_{i+1}-T i\right)\right]
$$

Em que:

n: é o número de observações.

$\mathrm{Y}_{\mathrm{i}}$ : é a severidade da doença na "i”- ésima observação;

$\mathrm{T}_{\mathrm{i}}$ : é o tempo em dias na "i"- ésima observação.

- Massa Seca das Raízes (\%): As amostras foram colocadas para secar a $65^{\circ} \mathrm{C}$ por $24 \mathrm{~h}$, conforme metodologia da AOAC (1985), por meio da fórmula:

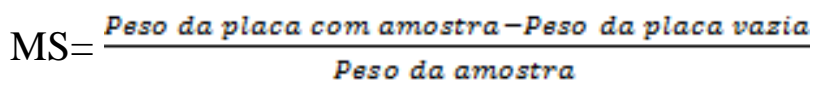

\section{Análise estatística dos dados}

Nos três experimentos foram realizadas análises de variância e as médias foram agrupadas pelo teste de Scott-Knott $(\mathrm{p}=0,05 \%)$ utilizando o programa estatístico SISVAR (FERREIRA, 2010). Nas comparações, os valores observados foram transformados para $\sqrt{(x}+1,0)$.

\section{RESULTADOS E DISCUSSÃO}

Seleção de isolados de Plenodomus destruens H. quanto à agressividade à genótipos de batata-doce

Houve interação significativa dos isolados com os genótipos BDFMI\#40 e 2007HSF1405. Em ambos os genótipos, o isolado que apresentou maior média para agressividade foi IMPG\#10, com tamanho médio da lesão de 2,34 cm, outros seis isolados também foram agrupados na mesma classe (Tabela 2). Os maiores valores de agressividade para o genótipo BDFMI\#40 foram observados nos isolados IMPG\#11 (2,70 cm), IMPG\#10 $(2,66 \mathrm{~cm})$, IMPP\#8 $(2,64)$ e IMPG\#2 $(2,37)$. Para o genótipo 2007HSF1405 o isolado mais agressivo foi o IMPG\#8 $(2,73 \mathrm{~cm})$ (Tabela 2).

A maioria dos isolados testados foi patogênica aos genótipos de batata-doce, apresentando os sintomas de mal-do-pé aos quatro dias após a inoculação, diferindo apenas quanto a severidade dos sintomas causados. Essas variações nas intensidades de crescimento da lesão do patógeno observadas neste trabalho podem estar associadas à disponibilidade de nutrientes presentes no substrato (hospedeiro) e afetarem diretamente a patogenicidade dos isolados, causando agressividade da doença, conforme constatado por Assis et al. (2001).

Contudo, observando-se os isolados de $P$. destruens e os dois genótipos de batatadoce, notou-se diferença no grau de suscetibilidade ou agressividade. Neste caso, Camargo e Cultura Agronômica, Ilha Solteira, v.27, n.2, p.287-301, 2018 
Bergamin Filho (1995) informam que o patógeno difere quanto à agressividade. Em estudos de seleção de isolados feitos por Alves (1998), a variação na agressividade foi observada com frequência, sendo relacionada à patogenicidade do isolado, à especificidade e à tolerância do hospedeiro, consequência da variabilidade genética de cada isolado.

Tabela 2. Médias para tamanho médio da lesão $(\mathrm{em} \mathrm{cm})$ em dois genótipos de batata-doce inoculados com isolados locais de mal-do-pé. Gurupi, UFT, 2014.

\begin{tabular}{lccc}
\hline Isolados & BDFMI\#40 & $\mathbf{2 0 0 7 H S F 1 4 0 5}$ & Médias $^{\mathbf{1}}$ \\
\hline IMPG\#1 & $1,00 \mathrm{Db}$ & $1,47 \mathrm{Ca}$ & $1,24 \mathrm{D}$ \\
IMPG\#2 & $2,37 \mathrm{Aa}$ & $2,07 \mathrm{Ba}$ & $2,22 \mathrm{~A}$ \\
IMPG\#3 & $2,15 \mathrm{Ba}$ & $1,05 \mathrm{Db}$ & $1,60 \mathrm{C}$ \\
IMPG\#4 & $1,00 \mathrm{Da}$ & $1,00 \mathrm{Da}$ & $1,00 \mathrm{D}$ \\
IMPG\#5 & $2,57 \mathrm{Aa}$ & $1,47 \mathrm{Cb}$ & $2,02 \mathrm{~A}$ \\
IMPG\#6 & $1,40 \mathrm{Ca}$ & $1,50 \mathrm{Ca}$ & $1,45 \mathrm{C}$ \\
IMPG\#7 & $1,99 \mathrm{Ba}$ & $1,67 \mathrm{Ca}$ & $1,83 \mathrm{C}$ \\
IMPG\#8 & $1,55 \mathrm{Cb}$ & $2,73 \mathrm{Aa}$ & $2,14 \mathrm{~A}$ \\
IMPG\#9 & $1,92 \mathrm{Ba}$ & $1,32 \mathrm{Cb}$ & $1,62 \mathrm{C}$ \\
IMPG\#10 & $2,66 \mathrm{Aa}$ & $2,02 \mathrm{Bb}$ & $2,34 \mathrm{~A}$ \\
IMPG\#11 & $2,70 \mathrm{Aa}$ & $1,63 \mathrm{Cb}$ & $2,17 \mathrm{~A}$ \\
IMPG\#12 & $2,16 \mathrm{Ba}$ & $1,70 \mathrm{~B}$ \\
IMPG\#13 & $1,24 \mathrm{Db}$ & $1,95 \mathrm{Ba}$ & $2,12 \mathrm{~A}$ \\
IMPG\#14 & $2,28 \mathrm{Ba}$ & $2,28 \mathrm{Ba}$ & $2,05 \mathrm{~A}$ \\
IMPP\#1 & $1,82 \mathrm{Bb}$ & $1,53 \mathrm{Ca}$ & $1,54 \mathrm{C}$ \\
IMPP\#2 & $1,55 \mathrm{Ca}$ & $1,35 \mathrm{Ca}$ & $1,17 \mathrm{D}$ \\
IMPP\#3 & $1,00 \mathrm{Da}$ & $1,88 \mathrm{Ba}$ & $1,53 \mathrm{C}$ \\
IMPP\#4 & $2,05 \mathrm{Ba}$ & $1,10 \mathrm{Da}$ & $1,49 \mathrm{C}$ \\
IMPP\#5 & $1,11 \mathrm{Db}$ & $1,08 \mathrm{Da}$ & $1,05 \mathrm{D}$ \\
IMPP\#6 & $1,00 \mathrm{Da}$ & $1,04 \mathrm{Db}$ & $1,27 \mathrm{D}$ \\
IMPP\#7 & $1,46 \mathrm{Cc}$ & $1,34 \mathrm{C}$ \\
IMPP\#8 & $1,64 \mathrm{Ca}$ & $1,95 \mathrm{Ba}$ & $1,86 \mathrm{~B}$ \\
IMPP\#9 & $2,64 \mathrm{Aa}$ & $1,43 \mathrm{C}$ \\
IMPP\#10 & $1,63 \mathrm{Cc}$ & $2,06 \mathrm{~A}$ \\
TEST & $2,13 \mathrm{Bb}$ & $1,00 \mathrm{D}$ \\
TEST+ALF & $1,00 \mathrm{Da}$ & $1,00 \mathrm{D}$ \\
\hline Média geral & $1,00 \mathrm{Da}$ & 1,62 \\
\hline C.V. (\%) & $1,79 \mathrm{a}$ & $\mathrm{Da}$ & \\
IMP & $\mathrm{Da}$ & \\
\hline & & 1,25 & $\mathrm{Da}$ \\
\hline
\end{tabular}

${ }^{1}$ Médias seguidas de mesmas letras maiúsculas na coluna e minúsculas na linha não diferem estatisticamente entre si pelo teste de Scott-Knott $(\mathrm{p} \leq 0,05)$. Valores transformados para $\sqrt{(x}+1,0)$.

Com base nos resultados, os isolados mais agressivos foram IMPG\#10, IMPG\#2, IMPG\#11, IMPG\#8, IMPG\#13, IMPP\#10, IMPG\#14 e IMPG\#5. Segundo Michereff et al. (2003), a agressividade de um isolado de um determinado patógeno está associada à velocidade no aparecimento dos sintomas da doença. Ou seja, quanto mais agressivo for 
determinado isolado, mais rápido será o aparecimento dos sintomas. Já o grau de suscetibilidade foi dado para o genótipo que apresentou maior porcentagem de infecção, sendo, neste caso, o genótipo BDFMI\#40. A reação diferenciada dos genótipos pode estar ligada às diferenças genéticas de cada uma, conforme relata Sharma e Dubin (1996).

\section{Suscetibilidade de genótipos de batata-doce à isolados locais de Plenodomus destruens H. em casa de vegetação}

Foram constatadas, pelo teste de Skott-Knott diferenças significativas $(\mathrm{P} \leq 0,05)$ para avaliação após a inoculação. Aos quatro dias após a inoculação foi possível distinguir que todos os genótipos apresentaram lesões marrons na haste, indicando assim que todos os materiais avaliados foram infectados pelos isolados, diferindo significativamente quanto ao tamanho da lesão (Tabela 3).

Nenhum genótipo foi imune à doença, porém foi possível distinguir diferentes níveis

de resistência. Resultados semelhantes foram obtidos por Pereira et al. (2013), que identificaram diferentes níveis de resistência em diversos cultivares avaliadas. Os genótipos BDFMI\#40 e 2007HSF1405 que manifestaram reação de suscetibilidade em laboratório, também tiveram a mesma reação em casa de vegetação. A cultivar Júlia foi a que apresentou maior média para os dois isolados $(1,34)$, indicando que este cultivar é mais suscetível à doença quando comparado aos demais genótipos avaliados.

Essa variabilidade entre os genótipos de batata-doce pode estar relacionada ao sistema reprodutivo da espécie, já que é uma planta que se propaga, essencialmente, de forma vegetativa e devido aos mecanismos de auto-incompatibilidade presentes e ploidia da espécie (OLIVEIRA et al., 2002). He et al. (2006) indicaram que o elevado nível da diversidade genética encontrada em acessos de batata-doce poderia ser o resultado de mutações espontâneas, que são bastante comuns nesta espécie, juntamente com seleção e fatores geográficos e ambientais, que tornam as populações locais da espécie um recurso genético importante. 
Tabela 3. Comprimento médio da lesão $(\mathrm{em} \mathrm{cm})$ em genótipos de batata-doce a dois isolados de mal-do-pé em condição de casa de vegetação. Gurupi, UFT, 2014.

\begin{tabular}{|c|c|c|c|}
\hline \multirow{2}{*}{ GENÓTIPOS } & \multicolumn{2}{|c|}{$\begin{array}{r}\text { Isolados } \\
\end{array}$} & \multirow{2}{*}{ Média Geral } \\
\hline & IMPG\#10 & IMPG\#11 & \\
\hline BDFMI\#04 & $1,07 \mathrm{Ca}$ & $1,15 \mathrm{Ba}$ & $1,11 \mathrm{D}$ \\
\hline BDFMI\#10 & $1,00 \mathrm{Da}$ & $1,00 \mathrm{Da}$ & $1,00 \mathrm{E}$ \\
\hline BDFMI\#11 & $1,06 \mathrm{Cb}$ & $1,32 \mathrm{Aa}$ & $1,19 \mathrm{C}$ \\
\hline BDFMI\#14 & $1,00 \mathrm{Da}$ & $1,00 \mathrm{Da}$ & $1,00 \mathrm{E}$ \\
\hline BDFMI\#16 & $1,10 \mathrm{Ba}$ & $1,09 \mathrm{Ca}$ & $1,09 \mathrm{D}$ \\
\hline BDFMI\#28 & $1,00 \mathrm{Da}$ & $1,02 \mathrm{Da}$ & $1,01 \mathrm{E}$ \\
\hline BDFMI\#31 & $1,06 \mathrm{Ca}$ & $1,00 \mathrm{Da}$ & $1,03 \mathrm{E}$ \\
\hline BDFMI\#36 & $1,02 \mathrm{Da}$ & $1,04 \mathrm{Ca}$ & $1,03 \mathrm{E}$ \\
\hline BDFMI\#38 & $1,04 \mathrm{Db}$ & $1,17 \mathrm{Ba}$ & $1,10 \mathrm{D}$ \\
\hline BDFMI\#40 & $1,08 \mathrm{Ca}$ & $1,09 \mathrm{Ca}$ & $1,09 \mathrm{D}$ \\
\hline BDFMI\#42 & $1,09 \mathrm{Ca}$ & $1,15 \mathrm{Ca}$ & $1,12 \mathrm{D}$ \\
\hline BDFMI\#51 & $1,08 \mathrm{Ba}$ & $1,07 \mathrm{Ca}$ & $1,08 \mathrm{D}$ \\
\hline BDFMI\#57 & $1,05 \mathrm{Da}$ & $1,00 \mathrm{Da}$ & $1,02 \mathrm{E}$ \\
\hline BDFMI\#58 & $1,00 \mathrm{Da}$ & $1,00 \mathrm{Da}$ & $1,00 \mathrm{E}$ \\
\hline BDFMI\#59 & $1,09 \mathrm{Ca}$ & $1,00 \mathrm{Da}$ & $1,05 \mathrm{E}$ \\
\hline BDFMI\#70 & $1,30 \mathrm{Ba}$ & $1,22 \mathrm{Ba}$ & $1,26 \mathrm{~B}$ \\
\hline BDFMI\#78 & $1,00 \mathrm{Da}$ & $1,08 \mathrm{Ca}$ & $1,04 \mathrm{E}$ \\
\hline BDFMI\#88 & $1,01 \mathrm{Da}$ & $1,01 \mathrm{Da}$ & $1,01 \mathrm{E}$ \\
\hline BDFMI\#89 & $1,01 \mathrm{Da}$ & $1,09 \mathrm{Ca}$ & $1,05 \mathrm{E}$ \\
\hline BDFMI\#93 & $1,09 \mathrm{Ca}$ & $1,04 \mathrm{Ca}$ & $1,06 \mathrm{D}$ \\
\hline BDFMI\#94 & $1,19 \mathrm{Ba}$ & $1,19 \mathrm{Ba}$ & $1,19 \mathrm{C}$ \\
\hline BDFMI\#106 & $1,00 \mathrm{Da}$ & $1,00 \mathrm{Da}$ & $1,00 \mathrm{E}$ \\
\hline 2007HSF0128 & $1,00 \mathrm{Da}$ & $1,00 \mathrm{Da}$ & $1,00 \mathrm{E}$ \\
\hline 2007HSF0613 & $1,00 \mathrm{Da}$ & $1,00 \mathrm{Da}$ & $1,00 \mathrm{E}$ \\
\hline 2007HSF0906 & $1,00 \mathrm{Da}$ & $1,00 \mathrm{Da}$ & $1,00 \mathrm{E}$ \\
\hline 2007HSF1031 & $1,07 \mathrm{Ca}$ & $1,04 \mathrm{Ca}$ & $1,06 \mathrm{D}$ \\
\hline 2007HSF1035 & $1,03 \mathrm{Da}$ & $1,12 \mathrm{Ba}$ & $1,07 \mathrm{D}$ \\
\hline 2007HSF1105 & $1,09 \mathrm{Ca}$ & $1,16 \mathrm{Ba}$ & $1,13 \mathrm{D}$ \\
\hline 2007HSF1405 & $1,09 \mathrm{Cb}$ & 1,33 Aa & $1,21 \mathrm{C}$ \\
\hline 2007HSF2210 & $1,04 \mathrm{Da}$ & $1,07 \mathrm{Ca}$ & $1,06 \mathrm{D}$ \\
\hline Duda & $1,02 \mathrm{Db}$ & $1,19 \mathrm{Ba}$ & $1,10 \mathrm{D}$ \\
\hline Itajuba & $1,00 \mathrm{Da}$ & $1,07 \mathrm{Ca}$ & $1,04 \mathrm{E}$ \\
\hline Júlia & $1,43 \mathrm{Aa}$ & $1,24 \mathrm{Bb}$ & $1,34 \mathrm{~A}$ \\
\hline Marcela & $1,22 \mathrm{Ba}$ & $1,15 \mathrm{Ba}$ & $1,18 \mathrm{C}$ \\
\hline Princesa & $1,15 \mathrm{Ca}$ & $1,07 \mathrm{Ca}$ & $1,11 \mathrm{D}$ \\
\hline Média Geral & $1,07 \mathrm{~b}$ & $1,09 \mathrm{a}$ & 1,08 \\
\hline C.V. (\%) & & 19,57 & \\
\hline
\end{tabular}

Médias seguidas de mesmas letras maiúsculas na coluna e minúsculas na linha não diferem estatisticamente entre si pelo teste de Scott-Knott $(\mathrm{p} \leq 0,05)$.

Cultura Agronômica, Ilha Solteira, v.27, n.2, p.287-301, 2018 
Produtividade, teor de massa seca e reação ao mal-do-pé em genótipos de batata-doce

Para as médias de produtividade foram observadas diferenças estatísticas entre os genótipos $(\mathrm{p} \leq 0,05)$. A produtividade entre os genótipos variou de 7,98 a 67,45 $\mathrm{Mg} \mathrm{ha}^{-1}$, destacando-se os genótipos BDFMI\#16 e Duda com produtividades de 67,45 e 55,42 Mg ha ${ }^{1}$, respectivamente. O genótipo que apresentou a menor produtividade foi o BDFMI\#70 (7,98 $\left.\mathrm{Mg} \mathrm{ha}^{-1}\right)$ (Tabela 4).

Tabela 4. Médias para produtividade e teor de matéria seca (MS) em genótipos de batatadoce em experimento de avaliação de resistência ao mal-do-pé. UFT, Gurupi, 2014.

\begin{tabular}{lll}
\hline GENÓTIPOS & PROD $\left(\mathbf{M g ~ h a}^{-\mathbf{1}}\right)$ & MS (\%) \\
\hline BDFMI\#04 & $52,25 \mathrm{~A}$ & $31,49 \mathrm{~B}$ \\
BDFMI\#10 & $39,46 \mathrm{~B}$ & $24,66 \mathrm{C}$ \\
BDFMI\#16 & $67,45 \mathrm{~A}$ & $28,12 \mathrm{C}$ \\
BDFMI\#31 & $40,72 \mathrm{~B}$ & $37,15 \mathrm{~A}$ \\
BDFMI\#38 & $27,22 \mathrm{C}$ & $26,91 \mathrm{C}$ \\
BDFMI\#40 & $33,33 \mathrm{C}$ & $33,00 \mathrm{~B}$ \\
BDFMI\#51 & $38,15 \mathrm{~B}$ & $28,59 \mathrm{C}$ \\
BDFMI\#57 & $23,57 \mathrm{C}$ & $24,20 \mathrm{C}$ \\
BDFMI\#70 & $7,98 \mathrm{C}$ & $33,80 \mathrm{~B}$ \\
BDFMI\#89 & $18,28 \mathrm{C}$ & $26,49 \mathrm{C}$ \\
BDFMI\#93 & $48,06 \mathrm{~B}$ & $25,61 \mathrm{C}$ \\
BDFMI\#94 & $28,55 \mathrm{C}$ & $32,70 \mathrm{~B}$ \\
BDFMI\#106 & $37,83 \mathrm{~B}$ & $32,73 \mathrm{~B}$ \\
2007HSF0128 & $44,17 \mathrm{~B}$ & $34,59 \mathrm{~B}$ \\
2007HSF1405 & $18,17 \mathrm{C}$ & $26,23 \mathrm{C}$ \\
Amanda & $20,56 \mathrm{C}$ & $27,52 \mathrm{C}$ \\
Duda & $55,42 \mathrm{~A}$ & $28,21 \mathrm{C}$ \\
Itajuba & $37,22 \mathrm{~B}$ & $38,19 \mathrm{~A}$ \\
Marcela & $21,35 \mathrm{~B}$ & $20,40 \mathrm{C}$ \\
Princesa & $21,39 \mathrm{C}$ & $25,76 \mathrm{C}$ \\
\hline C.V. (\%) & 28,72 & 9,58 \\
\hline Média Geral & 34,06 & 29,32 \\
\hline
\end{tabular}

${ }^{1}$ Médias seguidas pela mesma letra na coluna não diferem estatisticamente entre si pelo teste de Scott-Knott $(\mathrm{p} \leq 0,05)$.

Silveira (2008) em ensaios realizados no Tocantins durante dez anos com a cultura da batata-doce observaram que a produtividade média da cultivar Duda foi de $65,50 \mathrm{Mg} \mathrm{ha}^{-1}$. Este resultado foi superior ao encontrado no experimento, mostrando que a severidade da doença no campo pode ter acarretado na redução na produtividade desta cultivar. Comportamento semelhante foi verificado para a cv. Marcela, que apresentou produtividade

Cultura Agronômica, Ilha Solteira, v.27, n.2, p.287-301, 2018 
de 21,35 $\mathrm{Mg} \mathrm{ha}^{-1}$, mas Silva (2010) e Amorim et al. (2011) relataram produtividades de $33,04 \mathrm{Mg} \mathrm{ha}^{-1}$ e 29,82 $\mathrm{Mg} \mathrm{ha}^{-1}$, respectivamente.

Em estudo sobre identificação agronômica de genótipos de batata-doce em PalmasTO, Santana et al. (2013) encontraram valor de produtividade de 55,09 $\mathrm{Mg} \mathrm{ha}^{-1}$ para a cv. Duda, valor bem próximo para essa cultivar nesse experimento.

Para massa seca da raiz foram observadas diferenças estatísticas entre os genótipos $(\mathrm{p} \leq 0,05)$. A média do teor de matéria seca entre os genótipos variou de 20,39 a 38,19\%, destacando-se a cultivar Itajubá com 38,19\%. O que teve menor teor de matéria seca foi a cv. Marcela com 20,39\% (Tabela 5). De acordo com Leonel e Cereda (2002), o teor de matéria seca tem relação direta na produção de etanol e consequentemente, no rendimento industrial, o que ressalta a importância de selecionar genótipos com alto teor de matéria seca.

Tabela 5. Severidade e Área Abaixo da Curva de Progresso da Doença (AACPD) em genótipos de batata-doce em condições de campo em Gurupi, região sul do estado do Tocantins. UFT, Gurupi, 2014.

\begin{tabular}{lll}
\hline GENÓTIPOS & SEVERIDADE & AACPD \\
\hline BDFMI\#04 & $3,55 \mathrm{~A}$ & $15,82 \mathrm{~A}$ \\
BDFMI\#10 & $3,05 \mathrm{C}$ & $12,24 \mathrm{~B}$ \\
BDFMI\#16 & $3,44 \mathrm{~B}$ & $15,54 \mathrm{~A}$ \\
BDFMI\#31 & $3,57 \mathrm{~A}$ & $15,94 \mathrm{~A}$ \\
BDFMI\#38 & $3,96 \mathrm{~A}$ & $16,11 \mathrm{~A}$ \\
BDFMI\#40 & $2,68 \mathrm{E}$ & $11,47 \mathrm{~B}$ \\
BDFMI\#51 & $2,91 \mathrm{D}$ & $12,66 \mathrm{~B}$ \\
BDFMI\#57 & $2,65 \mathrm{E}$ & $11,40 \mathrm{~B}$ \\
BDFMI\#70 & $3,09 \mathrm{C}$ & $13,59 \mathrm{~B}$ \\
BDFMI\#89 & $3,42 \mathrm{~B}$ & $15,36 \mathrm{~A}$ \\
BDFMI\#93 & $3,19 \mathrm{C}$ & $14,00 \mathrm{~B}$ \\
BDFMI\#94 & $3,26 \mathrm{~B}$ & $14,44 \mathrm{~A}$ \\
BDFMI\#106 & $3,74 \mathrm{~A}$ & $17,10 \mathrm{~A}$ \\
2007HSF0128 & $3,93 \mathrm{~A}$ & $16,72 \mathrm{~A}$ \\
2007HSF1405 & $3,55 \mathrm{~A}$ & $16,02 \mathrm{~A}$ \\
Amanda & $3,29 \mathrm{~B}$ & $14,57 \mathrm{~A}$ \\
Duda & $3,73 \mathrm{~A}$ & $16,87 \mathrm{~A}$ \\
Itajuba & $3,14 \mathrm{C}$ & $13,63 \mathrm{~B}$ \\
Marcela & $3,34 \mathrm{~B}$ & $14,84 \mathrm{~A}$ \\
Princesa & $2,77 \mathrm{E}$ & $12,10 \mathrm{~B}$ \\
\hline Média Geral & 3,31 & 14,52 \\
\hline C.V. (\%) & 25,72 & 26,17 \\
\hline
\end{tabular}

${ }^{1}$ Médias seguidas pela mesma letra na coluna não diferem estatisticamente entre si pelo teste de Scott-Knott $(\mathrm{p} \leq 0,05)$.

Cultura Agronômica, Ilha Solteira, v.27, n.2, p.287-301, 2018 
A partir dos resultados obtidos é possível explorar a variabilidade existente em programas de melhoramento, de modo a combinar em um único genótipo características determinantes para a obtenção de altos rendimentos, resistência ao mal-do-pé e elevada produção de matéria seca.

Os primeiros sintomas da doença foram observados aos 120 dias após o transplante, coincidindo com o período de maior precipitação na região. Os primeiros sintomas observados foram aparecimento de lesões marrons escuras recobertas por pequenos pontos pretos na haste de todos os genótipos avaliados.

Alguns dos genótipos que apresentaram menor severidade da doença nas hastes, aos 140 dias após o transplante foram: Princesa $(2,55)$, BDFMI\#57 $(2,88)$ e BDFMI\#40 $(2,91)$. Já os que apresentaram maior severidade foram: Duda $(4,04)$, BDFMI\#106 $(4,03)$ e 2007HSF0128 (3,93) (Tabela 5).

Os genótipos BDFMI\#106 e Duda apresentaram os maiores valores de AACPD com 4,04 e 4,03, respectivamente. Os genótipos que apresentaram menores valores de AACPD foram Princesa, BDFMI\#40 e BDFMI\#57, com 12,10; 11,47 e 11,40, respectivamente.

De acordo com Miranda (1989); Lopes e Silva (1993) e Truta et al. (2000), a cultivar Princesa foi considerada como padrão de resistência ao mal-do-pé, contudo, esse comportamento não foi observado neste trabalho. Esses resultados são semelhantes aos resultados de Pereira et al. (2013).

Os genótipos BDFMI\#40 e 2007HSF1405 apresentaram comportamentos distintos em laboratório, casa de vegetação e campo de produção. De acordo com Carson et al. (2002), a relação patógeno-hospedeiro é distinta entre locais, sendo que, em campos de produção, frequentemente observa-se significativa interação entre genótipos e ambientes, podendo haver variação na severidade da doença devido à instabilidade dos locos de resistência na interação com o ambiente e/ou diferenças na população do patógeno entre os ambientes.

\section{CONCLUSÃO}

Os isolados IMPG\#10, IMPG\#11 e IMPG2 foram os mais agressivos em laboratório. Os genótipos de batata doce BDFMI\#10, BDFMI\#14, BDFMI\#58, BDFMI\#106, 2007HSF0128, 2007HSF0613, 2007HSF0906, BDFMI\#28, BDFMI\#88, BDFMI\#57, BDFMI\#31, BDFMI\#36, BDFMI\#78, Itajuba, BDFMI\#59 e BDFMI\#89 foram tolerantes ao mal do pé em casa de vegetação. Em campo, os genótipos mais produtivos foram BDFMI\#16, Duda, BDFMI\#04, BDFMI\#93 e 2007HSF0128, e os genótipos com maiores níveis de tolerância foram BDFMI\#57 e BDFMI\#40. 


\section{REFERÊNCIAS BIBLIOGRÁFICAS}

ANDRADE JÚNIOR, V. C.; VIANA, D. J. S.; PINTO, N. A. V. D.; RIBEIRO, K. G.; PEREIRA, R. C.; NEIVA, I. P; AZEVEDO, A. M.; ANDRADE, P. C. R. Características produtivas e qualitativas de ramas e raízes de batata-doce. Horticultura Brasileira, Brasília, v. 30, n. 4, p.584-589, 2012.

ALVES, S. B. Fungos Entomopatogênicos. In: ALVES, S. B. (Ed.). Controle microbiano de insetos. 2.ed. Piracicaba: FEALQ, 1998. cap. 11, p. 308-310.

AMORIM, L.; REZENDE, J. A. M.; BERGAMIN FILHO, A. Manual de fitopatologia: princípios e conceitos. 4.ed. São Paulo: Agronômica Ceres, 2011. v. 1. 704 p.

ASSOCIATION OF OFFICIAL AGRICULTURAL CHEMISTS - AOAC. Total dietary fiber in foods - Enzimatic-gravimetric method - First action. Journal Association Analytical Chemistis, Washington DC, v. 68, n. 2, p.20-399, 1985.

ASSIS, T. C.; MENEZES, M.; ANDRADE, D. E. G. T.; COELHO, R. S. B.; OLIVEIRA, S. M. A. Estudo comparativo de isolados de Colletotrichum gloeosporioides quanto ao efeito da nutrição de carboidratos no crescimento, esporulação e patogenicidade em frutos de três variedades de mangueira. Summa Phytopathologica, Jaboticabal, v. 27, n. 1, p.208212, 2001.

BARNETT, H. L.; HUNTER, B. B. Illustrated genera of imperfect fungi. 4.ed. St. Paul, MN: APS Press, 1998. $218 \mathrm{p}$.

BERGAMIN FILHO, A.; KIMATI, H.; AMORIM, L. Manual de Fitopatologia: Princípios e Conceitos. 3. ed. São Paulo: Ceres, 1995. 919 p.

CAMARGO, L. E. A.; BERGAMIN FILHO, A. Controle genético. In: BERGAMIN FILHO, A.; KIMATI, H.; AMORIM, L. (Eds). Manual de Fitopatologia: princípios e conceitos. 3.ed. São Paulo: Agronômica Ceres, 1995. cap. 1, p. 729-758.

CARSON, M. L., GOODMAN, M. M.; WILLIAMSON, S. M. Variation in aggressiveness among isolates of Cercospora from maize as a potential cause of genotype-environment interaction in gray leaf spot trials. Plant Disease, Saint Paul, v. 86, n. 10, p.1089-1093, 2002.

CAVALCANTE, M.; FERREIRA, P. V.; PAIXÃO, S. L.; COSTA, J. G.; PEREIRA, R. G.; MADALENA, J. A. Potenciais produtivo e genético de clones de batata-doce. Acta Scientiarum Agronomy, Maringá, v. 31, n. 3, p.421-426, 2009.

CAVALCANTI, L. S.; COÊLHO, R. S. B.; PEREZ, J. O. Reação de cultivares de batatadoce à podridão-do-pé, em condições de campo. Ciência Rural, Santa Maria, v. 32, n. 4, p.699-701, 2002.

Cultura Agronômica, Ilha Solteira, v.27, n.2, p.287-301, 2018 
CLARK, C. A.; HOLMES, G. L.; FERRIN, D. M. Major fungal and bacterial diseases. In: LOEBENSTEIN, G.; TROTTAPPILLY, G. (Ed.). The sweetpotato. Springer: Netherlands, 2009. cap. 1, p. 81-103.

DHINGRA, O. D.; SINCLAIR, B. J. Basic plant pathology methods. 2.ed. London: CRC 1995. $434 \mathrm{p}$.

EMPRESA BRASILEIRA DE PESQUISA AGROPECUÁRIA - EMBRAPA. Sistema brasileiro de classificação de solos. 3.ed. Brasília: Embrapa, 2013. 353 p.

FERREIRA, D. F. SISVAR - Sistema de análise de variância. Versão 5.3. Lavras-MG: UFLA, 2010. 1 CD-ROM.

FILGUEIRA, F. A. R. Novo Manual de Olericultura. Viçosa: UFV, 2008. 421 p.

GONÇALVES NETO, A. C.; MALUF, W. R.; GOMES, L. A. A.; GONÇALVES, R. J. S.; SILVA, V. F.; LASMAR, A. Aptidões de genótipos de batata-doce para consumo humano, produção de etanol e alimentação animal. Pesquisa Agropecuária Brasileira, Brasília, v. 46, n. 11, p.1513-1520, 2011.

HE, X.; LIU, Q. C.; ISHIKI, K.; ZHAI, H.; WANG, Y. P. Genetic Diversity and genetic relationships among Chinese Sweetpotato landraces revealed by RAPD and AFLP markers. Breeding Science, Beijing, v. 56, n. 2, p.201-207, 2006.

LEONEL, M.; CEREDA, M. P. (2002) Caracterização físico-química de algumas tuberosas amiláceas. Ciência e Tecnologia de alimentos, Campinas, v. 22, n. 1, p.65-69, 2002.

LOPES, C. A., SILVA, J. B. C. Management measures to control foot rot of sweet potato caused by Plenodomus destruens. International Journal of Pest Management, Bariloche, v. 39, n. 1, p.72-74, 1993.

MICHEREFF, R. J. NORONHA, M. A.; ROCHA JÚNIOR, O. M.; SILVA, J. A.; MIZUBUTI, E. S. G. Variabilidade de Isolados de Alternaria brassicicola no Estado de Pernambuco. Fitopatologia Brasileira, Brasília, v. 28, n. 6, p.656-663, 2003.

MIRANDA, J. E. C. Princesa: cultivar de batata-doce resistente ao "mal-do-pé" (Plenodomus destruens Harter). Horticultura Brasileira, Brasília, v. 29, n. 7, p.65-66, 1989.

NEVES, W. D. S.; DALLEMOLE-GIARETTA, R.; ZOOCA, R. J. F.; COUTINHO, M. M. Efeito de extratos botânicos sobre a eclosão e inativação de juvenis de Meloidogyne javanica e de $M$. incognita. Revista Trópica: Ciências Agrárias e Biológicas, Chapadinha, v. 4, n. 1, p.9-18, 2010.

OLIVEIRA, A. C. B; SEDIYAMA, M. A. N.; SEDIYAMA, T.; FINGER, F. L.; CRUZ, C. D. Variabilidade genética em batata-doce com base em marcadores isoenzimáticos. Horticultura Brasileira, Brasília, v. 20, n. 4, p.576-582, 2002.

Cultura Agronômica, Ilha Solteira, v.27, n.2, p.287-301, 2018 
PEREIRA, R. B.; FERNANDES, F. R.; PINHEIRO, J. B. Recomendações para manejo da podridão-do-pé em batata-doce. 1. ed. Brasília: EMBRAPA, 2011. 79 p. (Comunicado Técnico)

PEREIRA, R. B.; CARVAlHO, A. D. F.; PINHEIRO, J. B. Avaliação da resistência de cultivares de batata-doce ao mal-do-pé por meio de diferentes métodos de inoculação. Boletim de Pesquisa e Desenvolvimento 95. ed. Brasília: EMBRAPA. 2013. 16 p.

SANTANA, W. R.; MARTINS, L. P.; SILVEIRA, M. A.; SANTOS, W. F.; GONÇALVES, R. C.; SOUZA, F. R.; RESPLANDES, G. R. S.; LIMA, M. M. Identificação agronômica de genótipos de batata-doce em banco de germoplasma para fins industriais de etanol carburante. Tecnologia \& Ciência Agropecuária, João Pessoa, v. 7, n. 1, p.31-34, 2013.

SHARMA, R. C.; DUBIN, H. J. Effect of cultivar mixtures on spot blotch (Bipolaris sorokiniana) and grain yield. Field Crops Research, Kansas, v. 48, n. 2, p.95-101, 1996.

SHANER, G.; FINNEY, R. E. The effect on nitrogen fertilization on the expression of slowmildewing resistance in knox wheat. Phytopathology, Saint Paul, v. 67, n. 8, p.1051-1056, 1977.

SILVA, R. G. V. Caracterização físicoquímica de farinha de batata doce para produtos de panificação. 2010. 71 f. Dissertação (Mestrado em Engenharia de Alimentos) Universidade Estadual do Sudoeste da Bahia, Itapetinga, 2010.

SILVEIRA, M. A.; SOUZA, F. R.; ALVIM, T. C.; DIAS, L. E.; SANTANA, W. R.; VITAL M. K. G. S.; GOUVÊA, G. R. S. R.; COSTA, D. M. A cultura de bata-doce como fonte de matéria prima para etanol. Palmas: LASPER - UFT, 2008. 21 p. (Boletim Técnico).

SUTTON, B. C. The Coelomycetes. Fungi imperfecti with pycnidia, acervuli and stromata. Kew, UK: Commonwealth Mycological Institute, 1980. 696 p.

TRUTA, A. A. C.; ARAÚJO, E.; SILVA, V. F. Reações de cultivares e controle químico do mal-do-pé da batata-doce na microrregião do Brejo, Paraíba. Agropecuária Técnica, João Pessoa, v. 21, n. 1/2, p.18-23, 2000.

Cultura Agronômica, Ilha Solteira, v.27, n.2, p.287-301, 2018 